Dlouhy J., Binninger M., and Haghsheno S. (2019). "Buffer Management in Takt planning - An overview of Buffers in Takt Systems." In: Proc. $27^{\text {th }}$ Annual Conference of the International. Group for Lean

Construction (IGLC), Pasquire C. and Hamzeh F.R. (ed.), Dublin, Ireland, pp. 429-440. DOI: https://doi.org/10.24928/2019/0226. Available at: 〈www.iglc.net>

\title{
BUFFER MANAGEMENT IN TAKT PLANNING - AN OVERVIEW OF BUFFERS IN TAKT SYSTEMS
}

\author{
Janosch Dlouhy $^{1}$, Marco Binninger ${ }^{2}$ and Shervin Haghsheno ${ }^{3}$
}

\begin{abstract}
Takt Planning and Takt Control (TPTC) as a method for construction has the potential to reduce construction time in relation to normal scheduling without the increase of manpower. This leads to the question: what changes with the use of Takt planning? One theory is that Takt planning is using buffers more effectively than other schedule and planning methods. This paper provides an overview of the various buffers in Takt planning and describes how they can be used.
\end{abstract}

\section{KEYWORDS}

Lean construction, Buffer Management, Buffer, Takt, Takt planning.

\section{INTRODUCTION}

Takt planning and Takt steering is approached differently in construction projects all over the world. A number of the different approaches resume time reduction of the whole construction time that is planned with Takt planning (Kaiser 2013; Frandson et al. 2013; Binninger et al. 2018). One theory is, that buffers are used differentely and special buffers can be reduced. This paper summarizes the analysis of over 100 takted construction projects. Takt Planning and Takt Control is described as a method in other papers (Dlouhy et al. 2016; Binninger et al. 2017)

\section{THEORETICAL FOUNDATIONS}

In order identify the buffers properly in a construction schedule, it is important to define the buffers in a paper. There are many unique characteristics of buffers. The use of buffers (Howell and Ballard 1998; Horman and Kenley 1998), the method of production in a production system (Tommelein 1998); (Tommelein and Weissenberger 1999) and the use of capacity buffers to increase performance (Horman 2001) has been well described.

\footnotetext{
Lean Expert, BMW AG Munich, Germany, +49-721-695-245, janosch.dlouhy@kit.edu

Research Fellow, Karlsruhe Institute of Technology, Germany, +49-721-608-44124, marco.binninger@kit.edu

3 Professor, Karlsruhe Institute of Technology, Germany, +49-721-608-42646, shervin.haghsheno@kit.edu
} 
Literature for a detailed classification and differentiation of buffers in Takt Planning, however, could not be found.

In order to summarize all possible buffers, this paper considers the entire time allotted for a construction project. All hours, days and weeks are correlated to a specific construction area. As an example of this: every one $\mathrm{x}$ one square-meter area is linked to a single hour or one day. This approach shows in which areas, which work is being performed and where there are potential gaps. Because of its easy comprehensibility, a simplified Takt Plan (like in Figure 1) will be used as the basis for further observations.

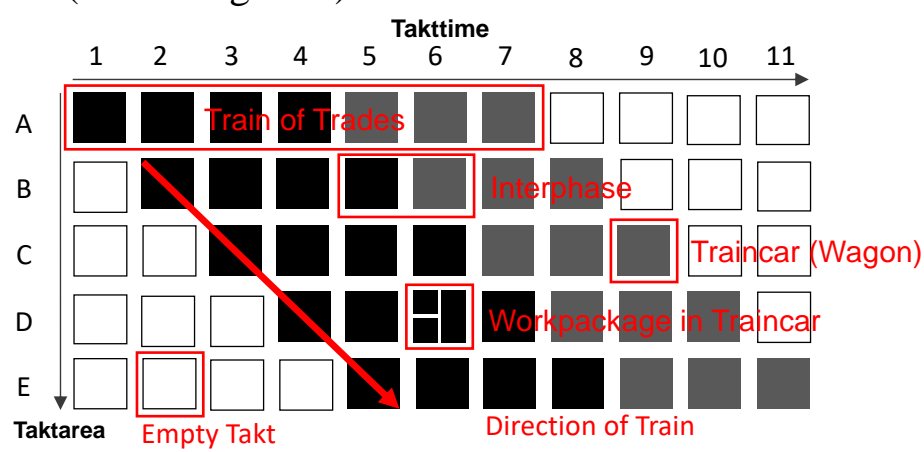

Figure 1: Takt Plan Pictogram

\section{METHODICAL APPROACH}

The buffer time represents a waiting time in a stable process, free of any external influences or hindrances, which equate to wastefulness. Nevertheless, buffers cannot be completely removed from a Takt plan. They must be properly dimensioned and located in a representative position (Poshdar et al., 2015, p.1). In non-stationary processes, such as the construction process, the use of moderate time buffers can increase the overall performance of the construction site processes (Sakamoto et al., 2002, p.11f.). More specifically, these buffers serve as factor of safety for budgeting costs, time scheduling, materials, storage, manpower and more. They can be used to compensate fluctuations or counteract resource shortages (see Alves and Tommelein 2004). Frandson et al. (2015, p.5) describes the formation of buffers through large areas of individual construction activities (lot sizes), in which schedule deviations are no longer visible.

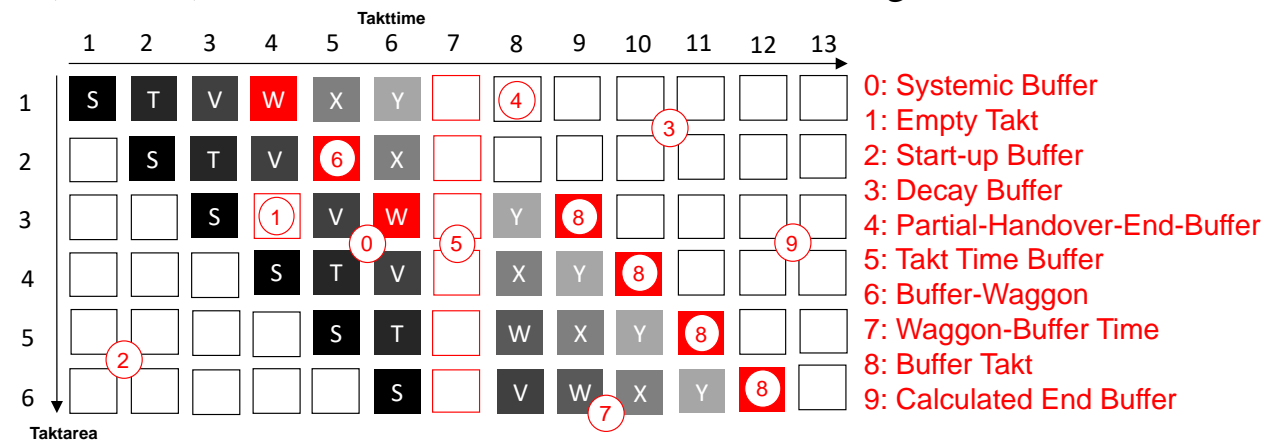

Figure 2: Types of Buffers

(0) The Systemic Buffer is an example of the weekend occurring at the end of each depicted calendar week. It is a buffer that the system naturally dictates, which does not 
have to be explicitly planned, but can be scheduled. At the scale of a daily Takt time, the buffer containing the weekend always occurs after 5 Takt times.

(1) The Empty Takt describes a Takt time in which no work is scheduled, yet Takt area is reserved. It can be planned or may occur unintentionally between individual wagons. Non-harmonized trades or overlooked restrictions may be responsible for this.

(2) The Start-up Buffer is the shift when starting Takt area after Takt area. It is a system dependent buffer that occurs based on the parameters of the system. It arises because the slope of the wagons has a limited extent (start-up curve). In principle, these areas are empty of value creation activity during the early Takts.

(3) The Decay Buffer is the counterpart of the start-up buffer. It is the result of the slope of the wagons in the trains ending in a pattern shifting the final wagon one Takt area further along the time scale, in relation to the offset at the beginning of the train. In principle, the area depicted represents empty, finished surfaces that no longer require subsequent work to be completed within them. Buffer types two and three are the largest single buffers in a project. They are not planned but are rather systemic. Reductions in this type of buffer have a high optimizing effect without causing the added value.

(4) The Partial-Handover-End-Buffer (PHEB) is the result of such an optimization. It is defined just as the total surface Decay Buffer, but only includes the triangle at the end of each cycle that shows a completed sub-project Area, that can be handed-over and where value creating activities can occur. In a Takt plan with 3 Takt areas, a partialhandover can occur 3 times after each completed train, creating in turn smaller partial handover buffers.

(5) A Takt-time Buffer affects a complete Takt time and can be either predictable (Christmas time, holidays or train stop) or might occur unplanned (weather conditions, strike or accident).

(6) A Buffer Wagon is the representation of a wagon in a trade train, in which no actual value creating process is undertaken. They are placed as placeholders for specific tasks or processes, such as the curing time, the replacement of machinery or the clearance of security areas. Buffer wagons can be placed at specific locations in the train's sequence.

(7) Wagon-Buffer Time defines the amount of buffer time within any given wagon. It is the difference between the floating buffer (Figure 16) and the amount of time required to perform the allotted tasks. After harmonization, any vacant time remaining in the wagon is considered to be a wagon-buffer. A wagon on a half-weekly cycle (2.5 days) might only be filled with 2 full days of work- the resulting Wagon-Buffer is a half day.

(8) The Buffer Takt is similar to the wagon-buffer in function, but varies in its location in the trade train. The Buffer Takt is placed at the end of a trade train sequence and is thereby no longer a part of the train. This type of buffer is often placed between two trains travelling consecutively in a single Takt area (e.g. between core and shell construction and the interior construction, or building construction and technical equipment installation.

(9) The Calculated End Buffer is the total cumulative time that can be saved from an optimized process flow. While this buffer may seem unnecessary at first glance, in reality it is deliberately planned. It communicates a general reserve of time that is at the project's 
disposal and which can be used, if the project requires it. If there is no need for its usage, it can be accounted for as time gained. This makes it the most effective type of buffer. By deliberately transforming buffers into the calculated-end buffers, projects can effectively gain time for the construction. In the Takt planning process, it is therefore important to set this transformation as a goal.

\section{RESULTS}

\section{LOT SIZE REDUCTION}

In construction, the lot size represents the size of the work areas (Takt areas) per Takt (Shim 2011, p.930). The number of Takt cycle times corresponds directly to this. By dividing the lot in half (effectively doubling the number of Takt areas, each with an area that has now half), the number of Takt cycles doubles (although the actual time per Takt has now been halved). Smaller lot sizes allow for lower risk, generate lower costs and deliver more visible results faster (see Reinertsen 2009), (Nielsen and Thomassen 2004, p.1). Lot size reduction (LSR) makes it possible to shorten the total time of a production process, improve the flow, control compliance with the plan is easier and the site is more flexible and easier to control (Valente et al., 2013, p.1037). Several authors have published papers about the effectiveness of LSR (Tommelein et al., 1999), (Alves and Tommelein 2004), (Dlouhy et al., 2017, p.7ff.). The general principle has been explained in the publications or illustrated by examples with clear, uniform subdivisions of small units of gaps (e.g., hotel or housing). In isolated publications, as in Ward and McElwee (2007) or Dlouhy et al. (2017), this effect has also been applied to building structures that are not uniform and do not contain standard repetitive elements. These papers focus on projects, in which the smallest common denominator is not always clear- supermarkets (Ward and McElwee 2007, p.547), (Dlouhy et al. 2017, p.8) or the production properties considered here. The LSR makes it possible to present waiting times transparently, that is time in which no work takes place on a small area of the total project (Ward and McElwee 2007). For this purpose, tools for visualization, such as "Line of Balance" (LOB) or the Takt plan can be used. In Figure 3, the lot size reduction is shown schematically using a timing diagram. Number one shows a classic sequence of work processes (w, x, y, z) one behind the other with a large lot size (one clock range). In number two, the total work is divided into three smaller Takt areas. The sequence of work processes remains. In the third image, the work processes are sequenced with the smaller lot size. The result shows how this example reduces the initial twelve cycle times to six, which corresponds to a relative time reduction of $50 \%$.

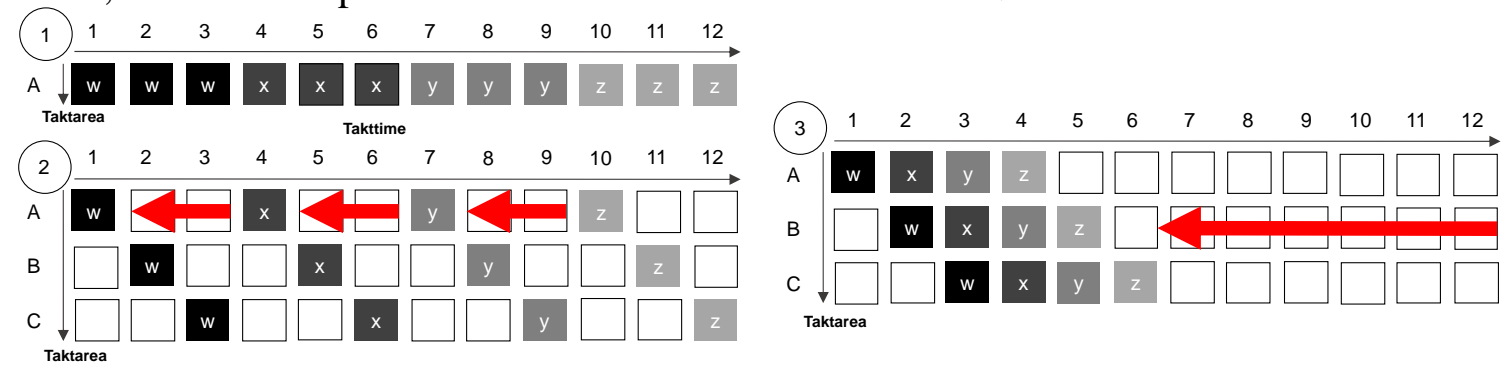


Figure 3: Lot size reduction effect

The actual reduction effect arises from the earlier beginning of the individual work contents. Actual working hours are not shortened. However, because of the earlier handover of the smaller Takt areas, subsequent work is able to be carried out much sooner. Although further divisions into smaller area units offer renewed optimization potential. These potentials are reduced with each subsequent application (decreasing marginal utility). Figure 4 shows the application of the lot size reduction in combination with Takt time reduction. In the first step, work is shown without overlap. Step 2 shows a typical example of a schedule with a 50\% overlap of work. Number 3 visualizes the initial implementation of Takt planning. Number 4 shows a doubling number of Takt areas, and the resulting halving of Takt time (smaller areas require less time to accomplish work). Number 5 shows a further halving of Takt area and Takt cycle time. From the classic scheduling (number two) to the small lot size of Takt planning, the lead time is reduced from 25 to 7.25 weeks, which corresponds to a reduction of $71 \%$.

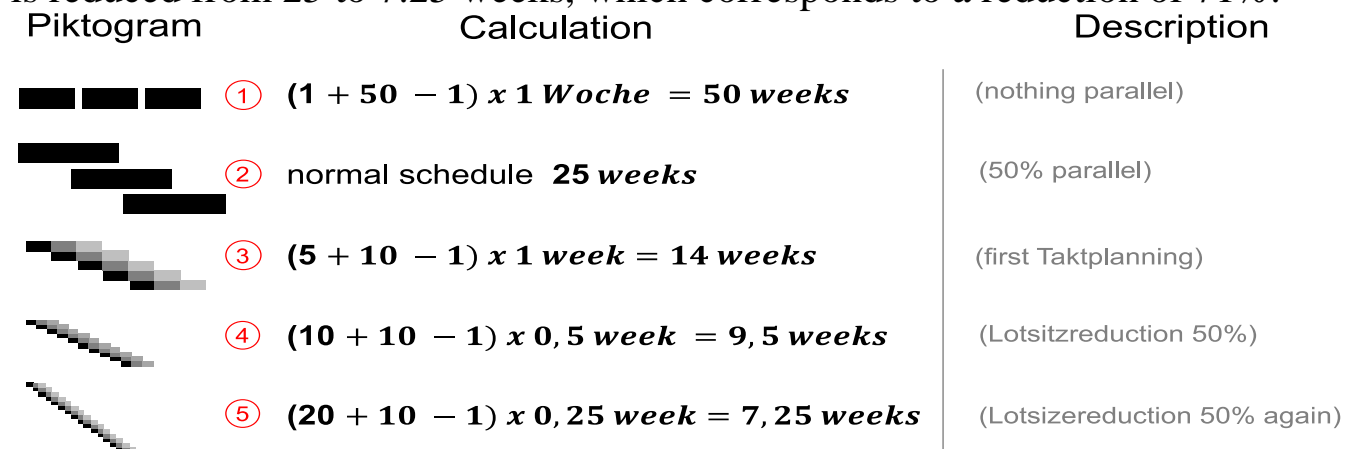

Figure 4:1 Effectiveness of lot size reduction in combination with Takt time reduction

\section{Side Effects}

A lot size reduction of $50 \%$ produces a Takt increase equivalent to the factor of four or $400 \%$. This massive increase in Takt creates increased control effort. Additionally, the number of movements of the trades doubles due to the halved Takt time. This increase must remain manageable, while the system increases in complexity. The stability of the processes can be jeopardized as the reduction of the Takt time also reduces the reaction time. However, the added value per Takt cycle time is increased. Figure 5 illustrates this relationship with an example of a ten wagon train, where multiple Takt halving has been performed, in combination with area division.

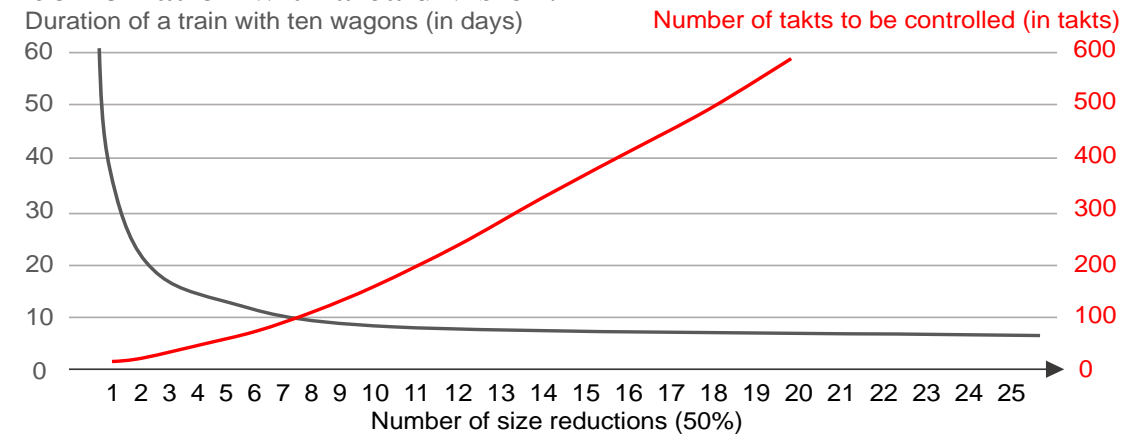

Figure 5: Reduction of total duration compared to the total number of Takts 


\section{Parallelization}

In Takt planning, parallelization takes place by bundling work packages in a wagon. The various trades work simultaneously in the same area. Work, however, can only be carried out in parallel if sufficient processing units are available for its execution. Additionally, there can be no dependence to previously carried out regular work. Previous work package must be completed in order for the next to be allowed to begin. If a parallelization succeeds, the Takt times are reduced, which corresponds to an effective time gain.

The takting of train of trades produces the effect of parallelizing individual building process steps (e.g., work packages in core/shell, mechanical, finishing, etc.). Process steps usually consist of sub-processes, which in turn can be executed successively or in parallel. An example would be the decoupling of wagons and allowing parallel execution of work packages. This effect is summarized under Wagonisation.

The Lot size reduction (LSR) is another form of parallelization. By reducing the size of the Takt area $\left(\mathrm{m}^{2}\right)$, individual work steps are cycled through earlier. The overlapping of time periods for the individual trades is also considerably parallelized. Work that has yet to be takted or scheduled (workable backlog) must be performed after the takted work has been completed. By completing these untakted work packages within the defined Takt periods, a higher level of parallelization is achieved. In order for this to work, excess time (buffers) in the wagons must be identified, which can then be used to finish the workable backlog. The various types of parallelization are depicted in figure 6 . Number 1 shows Lot size reduction. 2 shows the wagonization of various work packages. 3 depicts two trains running in parallel. Number 4 shows the synchronization of work from the workable backlog into the Wagon Buffer-time.

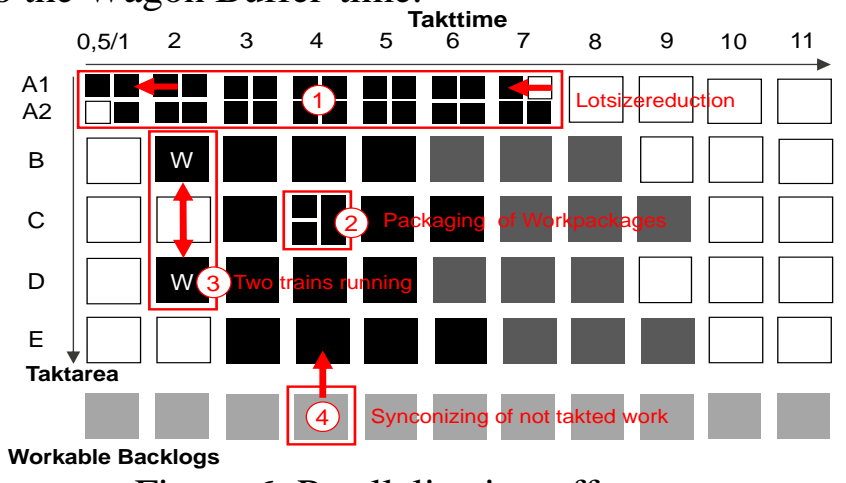

Figure 6: Parallelization-effect

\section{Side Effects}

The parallelization means that more work packages are completed simultaneously either in the same Takt area or Takt period. A high concentration of work, caused by high levels of parallelization, can lead to a disruption of individual work processes.

This concentration can lead to a disruption of the individual work, if the parallelization reaches a critical point. The coordination and control effort increase significantly with intensive use. The supply of material and resources must be guaranteed. 
The benefit of this extra effort, however, is great as the added value share per Takt increases.

\section{HARMONIZATION}

Harmonization can take place within a wagon, within a train or even within a project with several trades. The harmonization of the wagons has the intended goal to produce a uniform distribution of the work contents. Through a balanced distribution of work, the trades can complete their work unhindered within their specific Takt area. This creates a continuous stream or flow of work.

The harmonization can be calculated and adjusted by manipulating the workforce and work content. Further mechanisms for adjustment include prefabrication or other classical acceleration measures (see Körtgen 2010, pp. 31f). The targeted use of buffers can also be used for harmonization. Figure 7 shows what time potentials can arise from the harmonization of trains. Each of the five trades is on site for the same amount of time in both scenarios, yet in the Takt plan example 4 Takt cycle (just about $29 \%$ of the total duration) can be saved. The Gantt chart (Graphic1), in which there is already a certain degree of parallelism (though independent from specific area) is transferred to the Takt plan, shown in graphic 2.

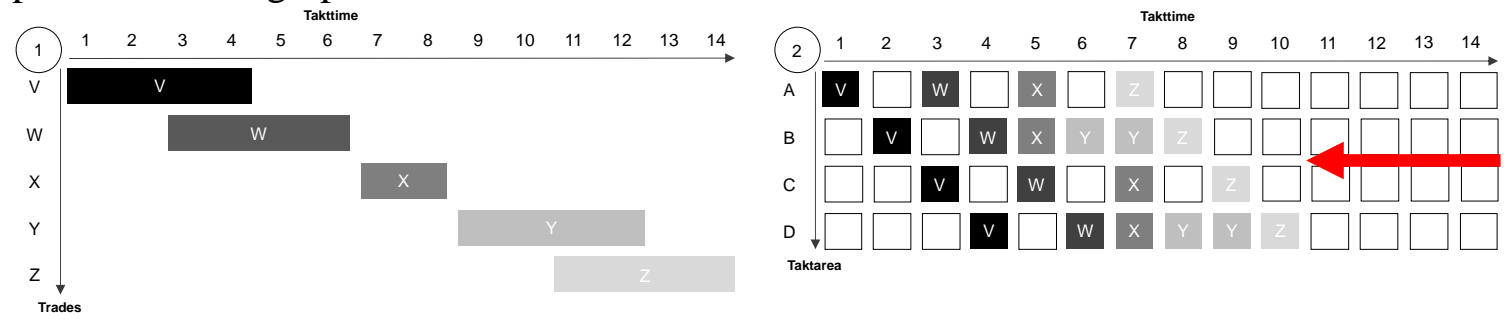

Figure 7: Harmonization-Effect

\section{Side Effects}

Improper harmonization inevitably leads to under- or overuse of workers. Underuse creates waiting times, alternate work, as well as requires increased control effort. Waiting times lead to the consumption of buffer times and alternate work can disturb the work of other trades. The overuse leads to a misconduct of the Takt targets. As a result, the work of the next car will be delayed in the next Takt cycle, resulting in disabilities in the workflow.

\section{FLOW-BASED REPETITION}

The harmonization of the train of trades, with its work package wagons (railcars), allows work to proceed in a continuous cycle with regulated flow. This generates a steady stream of value creation for the construction project, not only for the individual trade, but for all trades together. The goal is to reduce waiting times for workers or machines and avoid accumulation of material or work in progress (Faloughi et al., 2015, p.164ff.).

The flow-based repetitive effect can be generated on construction sites and communicated transparently. Regardless of how many trades or work packages are located in a wagon, the trades move from Takt area to Takt area, throughout the project in 
a repetitive process (see also Figure 8). Even if the flow-repetition is not clearly visible, as in the second graphic of Figure 8, it is still possible to identify a repetition.
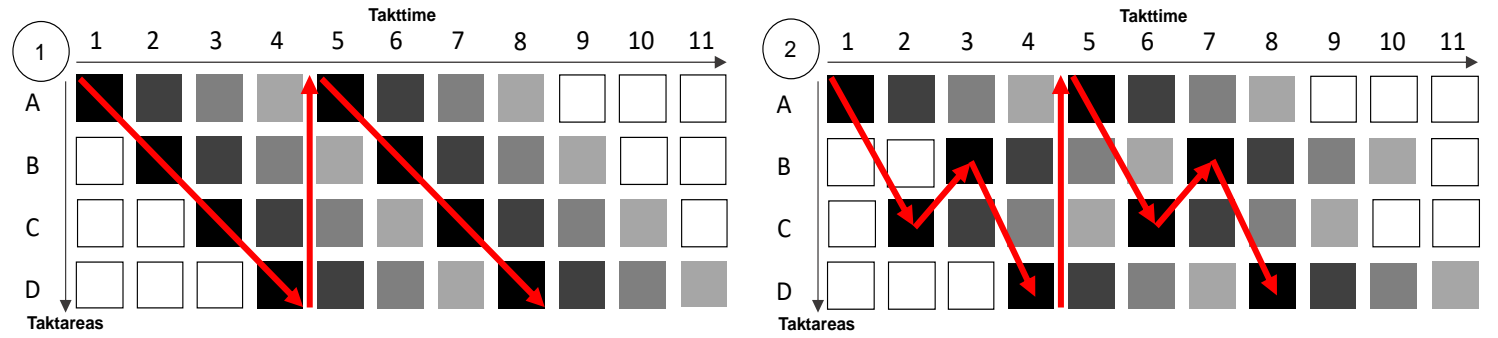

Figure 8: Flow-based Repetition

\section{Side Effects}

While repetition provides the benefit of learning from- and preparing for future Takts, it can also lead to an oversimplified routine for the workers. This can result in mental fatigue, especially at short Takt cycles.

\section{WAgONISATION}

The Wagonisation represents a kind of parallelization at the level of the trades. A wagon describes a receiving unit for work packages in a train of trades. It is a container defined by a single takt area in a single Takt time. It is defined by amount of time within one Takt cycle time. Work packages can be combined in these 'containers'. The work packages may have different relationships; they can either build upon one another or work side by side. Cumulative work is combined based on workload. Trades that can run side by side are harmonized individually. A wagon contains at least one work package (step 5 of the TTPTS), except when it is an empty buffer wagon (eg. drying times). If several work packages can be executed in parallel, in a specific Takt, these units can also be combined in one wagon. By allowing the trades to work together and individual wagons to be combined, the total completion time is reduced (as shown in Figure 9). In the example shown below, three Takts have been combined in illustration 2, thus generating $30 \%$ time saving compared to Figure 1.
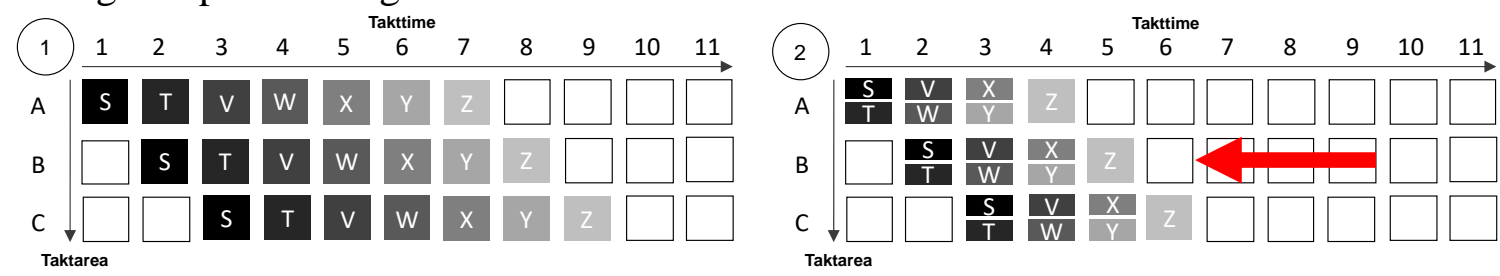

Figure 9: Wagonisation

\section{Side Effects}

Incorrect wagonisation may cause interferences between the trades working together, which may have an effect on their performance.

\section{LONG LEAD MECHANISM}

In the case of the long-runner mechanism, time-consuming process sequences are started at an early stage, which allows a maximum processing period until the end of the project. 
Although this effect often considered in construction projects, it is rarely described methodically. In order for this effect to be made transparent, location-based scheduling is required for the identification of the long-running processes. As depicted in figure 10, this effect can ensure an optimized overall project duration. By prioritizing Takt area $\mathrm{C}$, two cycle times or $22 \%$ of the total duration can be saved, as depicted in the second example.
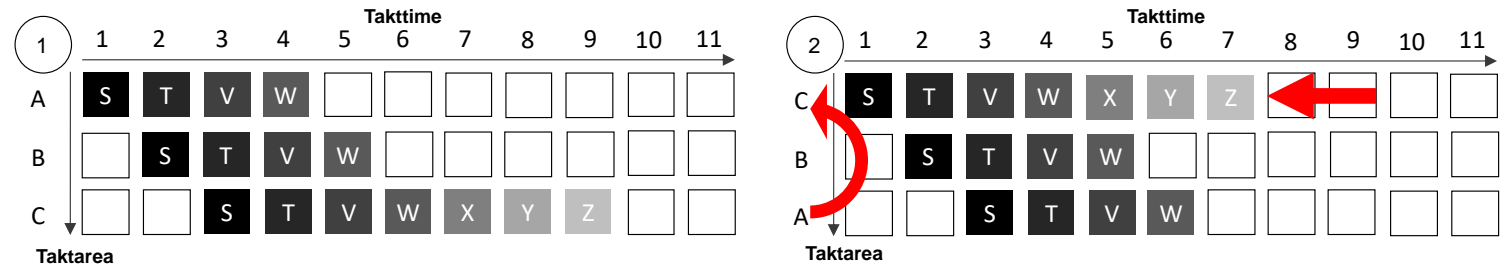

Figure 10: Long Running Process

In addition to the time advantage of prioritizing, long running processes and a customeroriented planning of the construction processes, ensures the partial area prioritization goals of the client are delivered. For this purpose, the user or the client must be involved in determining which areas contain installations which require the longest construction time.

\section{Side Effects}

The prioritization of long running processes restricts the customer prioritization of areas and can lead to technical problems in the process.

\section{All OVER USAge OF Buffers in TAKT PlanNing}

The method and visualization of Takt planning shows a different usage of buffers like common scheduling. Buffers are mathematically designed. All other buffers get excluded. While projects are not stable in realisation than planning is, buffers are installed in the project time which makes them passive time that will be wasted if the buffer was not necessary. Also, Takt projects show volatility in realisation. For that reason, these additional buffers where installed behind the normal schedule to get an active buffer that could be used for any situation. With this approach, just buffers are used, which are needed and there is always an overview over the calculated end buffer. Figure 11 shows the visualization in a Takt schedule.

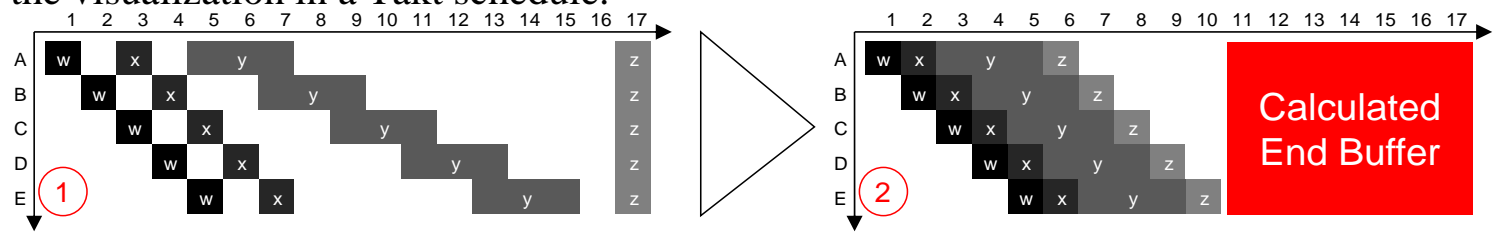

Figure 11: Using the Calculated End Buffer in scheduling

\section{DISCUSSION AND CONCLUSION}

Buffers are not just waste that can be eliminated; there is a correlation between the performance of a project and the use of buffers (Sakamoto et al., 2002, p.11f.). Through 
the visualization of buffers in a Takt schedule, the buffers become a part of the Takt process and integrated into a Takt area. Too many buffers within a project are waste. The paper shows an overview of all detected buffers during 100 projects and the different ways to optimize these buffers. With this foundation in buffer management for Takt planning, construction schedules could be more stable and efficient.

\section{REFERENCES}

Alves, Thais da C. L.; Tommelein, Iris D. (2004), „Simulation of Buffering and Batching Practices in the Interface Detailing-Fabrication-Installation of HVAC Ductwork". In: Proceedings of the 12th Annual Conference of the International Group for Lean Construction. Helsingør, Denmark.

Binninger, M., Dlouhy, J., and Haghsheno, S. (2017). "Technical Takt Planning and Takt Control in Construction." 25th Annual Conference of the International Group for Lean Construction, Heraklion, Greece, 605-612.

Binninger, M. , Dlouhy, J. , Müller, M. , Schattmann, M. \& Haghsheno, S. (2018), 'Short Takt Time in Construction - a Practical Study' In:, 26th Annual Conference of the International Group for Lean Construction. Chennai, India, 18-20 Jul 2018.

Dlouhy, J., Binninger, M., Oprach, S., and Haghsheno, S. (2016). "Three-Level Method of Takt Planning and Takt Control - a New Approach for Designing Production Systems in Construction." Proceedings of the 24th Annual Conference of the International Group for Lean Construction, Boston, USA, 13-22.

Faloughi, Mazen; Linnik, Meeli; Murphy, Dan; u. a. (2015), „WIP Design in a Construction Project Using Takt Time Planning“". In: Proceedings of the 23rd Annual Conference of the International Group for Lean Construction., S. 163-172.

Frandson, A., Berghede, K., and Tommelein, I. D. (2013). "Takt Time Planning for Construction of Exterior Cladding." 21th Annual Conference of the International Group for Lean Construction, Fortaleza, Brazil, 527-536.

Frandson, Adam G.; Seppänen, Olli; Tommelein, Iris D.; u. a. (2015), „Comparison between Location Based Management and Takt Time Planning“. In: 23rd Annual Conference of the International Group for Lean Construction. Perth, Australia, S. 312.

Horman, Michael; Kenley, Russell (1998), „Process Dynamics: Identifying a Strategy for the Deployment of Buffers in Building Projects“. In: International Journal of Logistics Research and Applications. 1 (3), S. 221-237, DOI: 10.1080/13675569808962049.

Horman, Michael J. (2001), „Modeling the Effects of Lean Capacity Strategies on Project Performance“. In: Proceedings of the 9th Annual Conference of the International Group for Lean Construction. Singapore, Singapore.

Howell, Greg; Ballard, Glenn (1998), „Implementing Lean Construction: Understanding and Action". In: Proceedings of the 6th Annual Conference of the International Group for Lean Construction (IGLC 6), Guaruja, SP. Guaruja, Brasil.

Kaiser, J. (2013). Lean Process Management in der operativen Bauabwicklung. [Lean Process Management in operational execution of construction work] Schriftenreihe des Instituts für Baubetrieb, Inst. für Baubetrieb, Darmstadt. 
Körtgen, Manfred (2010), Optimierungsansätze zur prozessorientierten Abwicklung komplexer Baumaßnahmen unter Einsatz neuer Informations- und Kommunikationssysteme. Kassel: Kassel Univ. Press (Schriftenreihe Bauwirtschaft 1, Forschung). - ISBN: 978-3-89958-929-0

Nielsen, Anni Schmidt; Thomassen, Mikkel Andreas (2004), „How to Reduce Batch Size“. In: Proc., 12th Annual Conf. of the Int. Group for Lean Construction (IGLC12).

Poshdar, M.; González, V. A.; Belayutham, Sheila (2015), „An Inclusive Probabilistic Buffer Allocation Method“. In: Proceedings of the 23rd Annual Conference of the International Group for Lean Construction. Perth, Australia, S. 183-192.

Reinertsen, Donald G. (2009), The Principles of Product Development Flow: Second Generation Lean Product Development. 1. Aufl. Redondo Beach, Calif: Celeritas Publishing. - ISBN: 978-1-935401-00-1

Sakamoto, Masanobu; Horman, Michael J.; Thomas, H. Randolph (2002), „A Study of the Relationship between Buffers and Performance in Construction“. In: Proceeding of the Tenth Annual Conference of the International Group for Lean Construction. Gramado, Brazil.

Shim, Euysup (2011), „Impacts of matched batch sizes on time reduction in construction projects.“. In: Proceedings of the 28th International Symposium on Automation and Robotics in Construction., S. 929-934.

Tommelein Iris D. (1998), „Pull-Driven Scheduling for Pipe-Spool Installation: Simulation of Lean Construction Technique“. In: Journal of Construction Engineering and Management. 124 (4), S. 279-288, DOI: 10.1061/(ASCE)07339364(1998)124:4(279).

Tommelein, Iris D.; Weissenberger, Markus (1999), „More Just-in-Time: Location of Buffers in Structural Steel Supply and Construction Processes“. In: Proceedings of the 7th Annual Conference of the International Group for Lean Construction., S. 109120.

Valente, Caroline P.; Montenegro, Germano A.; Brito, Felipe L.; u. a. (2013), „Benefits of Batch Size Reduction: A Case Study in a Residential Project". In: Proceedings of the 21th Annual Conference of the International Group for Lean Construction., S. 1029-1038.

Ward, Steven A.; McElwee, Ward (2007), „Application of the Principle of Batch Size Reduction in Construction“. In: 15th Annual Conference of the International Group for Lean Construction., S. 539-548. 